\title{
Multidecadal Variability in Global Surface Temperatures Related to the Atlantic Meridional Overturning Circulation ${ }^{\mathscr{O}}$
}

\author{
Martin B. Stolpe, Iselin Medhaug, Jan SedláčeK, and Reto Knutti \\ Institute for Atmospheric and Climate Science, ETH Zürich, Zurich, Switzerland
}

(Manuscript received 30 June 2017, in final form 5 January 2018)

\begin{abstract}
Multidecadal internal climate variability centered in the North Atlantic is evident in sea surface temperatures and is assumed to be related to variations in the strength of the Atlantic meridional overturning circulation (AMOC). In this study, the extent to which variations in the AMOC may also alter hemispheric and global surface air temperature trends and ocean heat content during the past century is examined.

Forty-seven realizations of the twentieth-century climate change from two large ensembles using the Community Earth System Model (CESM) are analyzed. One of the ensembles shows a much wider spread in global mean surface air temperature between its members. This ensemble simulates diverging trends of the AMOC strength during the twentieth century. The presence and strength of deep convection in the Labrador Sea controls these trends. The AMOC strength influences the air-sea heat flux into the high-latitude ocean, where a strengthening of the AMOC leads to decreased storage of heat in the Atlantic, and a larger fraction of the heat taken up by the global ocean accumulates in the top $300 \mathrm{~m}$, compared to the case of a weakening AMOC. The spread in the amount of heat stored in the global ocean below $300 \mathrm{~m}$ is similar across the CESM members as in a set of CMIP5 models, confirming the AMOC as a "control knob" on deep-ocean heat storage. By influencing the ocean heat uptake efficiency and by shifting the pattern of heat uptake, global surface air temperatures are significantly altered on a multidecadal time scale by AMOC variability.
\end{abstract}

\section{Introduction}

The observed warming of climate since the beginning of the industrial era is, in principle, a combination of internal climate variability and a forced signal. The internal variability is generally not in phase in climate models and observations, which impedes the comparison of the two not only on a regional scale (Deser et al. 2012), but also on a decadal time scale for global mean surface air temperatures (Knutson et al. 2016; Medhaug et al. 2017). One way to examine the role of internal variability is to repeat climate model simulations with different initial conditions to create large ensembles of possible realizations of twentieth-century climate change. Each realization is forced with the same historical forcing, and the simulations, therefore, only

\footnotetext{
Supplemental information related to this paper is available at the Journals Online website: https://doi.org/10.1175/JCLI-D-170444.s1.

Corresponding author: Martin B. Stolpe, martin.stolpe@env. ethz.ch
}

differ in their modeled internal variability if the two add up linearly. The modeled internal variability also differs between climate models, and the actual (partly unknown) internal variability of the climate system again might be different. Two ways to generate such ensembles exist in principle (Stainforth et al. 2007; Hawkins et al. 2016): either very small random perturbations are used to generate "micro" ensembles from the same initial climate state, or the ensemble members are branched off from different climate states of a control simulation ("macro" ensembles). The micro ensemble members become sufficiently different after a few years (for most surface variables) to decades (for ocean properties) as they lose their initial condition memory and are assumed to finally reach a similar spread as the macro ensemble members.

The high-latitude oceans have been identified as a key region for interdecadal to multidecadal variability in surface air temperature on hemispheric and global scales (Brown et al. 2016). In particular, variability in the Atlantic meridional overturning circulation (AMOC) is relevant. At $26.5^{\circ} \mathrm{N}$, the Atlantic Ocean transports around 1.3 PW of heat northward (Johns et al. 2011), 
and at that latitude, variations in the strength of the AMOC are linearly related to changes in the heat transported (Johns et al. 2011; Msadek et al. 2013), thereby leading to changes in the North Atlantic sea surface temperature (SST) through heat convergence and divergence (e.g., Delworth et al. 1993; Delworth and Mann 2000; Marini and Frankignoul 2014; Tandon and Kushner 2015; Buckley and Marshall 2016). The associated lower-frequency variability in North Atlantic SST is commonly termed the Atlantic multidecadal variability (AMV) (Farneti 2017).

The AMOC influences ocean heat uptake: a weakening of the AMOC (reversed for a strengthening AMOC, but for simplicity, this is not explicitly mentioned in the following) has been linked to increased ocean heat uptake through enhanced stability in the high-latitude ocean (Gregory 2000; Knutti and Stocker 2000; Raper et al. 2002; Rugenstein et al. 2013; Winton et al. 2013; Marshall and Zanna 2014; Drijfhout 2015). An increase in high-latitude heat uptake, where the feedbacks are strong, is most effective at altering global mean surface air temperatures (GMST) (Winton et al. 2010; Rose et al. 2014; Rugenstein et al. 2016; Garuba et al. 2018; Haugstad et al. 2017).

The sensitive climate at high latitudes has been tied to different atmospheric and cryospheric feedbacks. Trossman et al. (2016) argue that a declining AMOC leads to an increased meridional SST gradient in the North Atlantic Ocean (Winton 2003). This enhanced gradient leads to strengthened North Atlantic storm tracks (Woollings et al. 2012). This results in increased downward vertical velocity anomalies equatorward of the jet and enhanced boundary layer inversion strength (Grise and Medeiros 2016). The increased vertical stability of the lower troposphere reduces the entrainment of dry, upper-tropospheric air into the lower troposphere and increases low cloud coverage (Klein and Hartmann 1993; Wood and Bretherton 2006). The increase in low cloud coverage amplifies and propagates the initial cooling of an AMOC decline (Zhang et al. 2010; Trossman et al. 2016). The cooling is further strengthened through the sea ice albedo feedback, since sea ice in the Atlantic sector of the Arctic tends to expand after an AMOC weakening (Mahajan et al. 2011; Day et al. 2012; Yeager et al. 2015; Zhang 2015), and by the decreased atmospheric water vapor content (Laurian et al. 2009).

There are differing views on whether, and by how much, AMOC variability induces North Atlantic SST variability and contributes to variations in temperature on a hemispheric and even on a global scale. Clement et al. (2015) note that mixed layer ocean simulations produce a similar AMV to fully coupled models in terms of variance, pattern, and frequency, implying that ocean circulation variability does not play a role in North
Atlantic variability. This view, however, has been challenged by showing that the mixed layer ocean simulations lack key elements of the observed AMV (O'Reilly et al. 2016; Zhang et al. 2016; Delworth et al. 2017), and too-weak simulated multidecadal variability in the North Atlantic Oscillation (NAO) has been proposed as a reason why some coupled models could underestimate multidecadal AMOC and, accordingly, North Atlantic SST variability (Kim et al. 2018). Delworth and Zeng (2016) and Delworth et al. (2016) prescribe surface heat flux patterns that resemble the observed NAO. They find that NAO variations alter the AMOC and thereby may be important to explain the observed multidecadal Northern Hemisphere surface temperature variability. Stolpe et al. (2017) search for periods from unforced control simulations that agree with the observed AMV, show that the AMOC is strengthened in a positive AMV phase, and estimate, based on these variability analogs, that Atlantic variability contributes to multidecadal variability in Northern Hemisphere and global temperatures.

Since 2004, AMOC strength has been continuously measured at $26.5^{\circ} \mathrm{N}$ (Cunningham et al. 2007), but for earlier periods, ocean reanalyses, fingerprints (patterns in the climate system that are assumed to be associated with the AMOC and its strength), and indirect proxies are used to reconstruct the AMOC. These reconstructions show conflicting results for the strength of the AMOC prior to 2004 (Buckley and Marshall 2016). This complicates the assessment of the potential role of AMOC variability on observed multidecadal variations in the twentieth-century air temperatures. Here, large, multimember climate model ensembles are helpful to examine how different, but still plausible, AMOC evolutions might have influenced the climate and how they will continue to do so.

In this study, we compare two large ensembles (one macro and one micro ensemble) of the Community Earth System Model version 1 (CESM1), each of which only differs in its initial conditions. One of the two large ensembles simulates an increased spread in decadal GMST among its members during the midtwentieth century (Fig. 1a, blue ensemble). This becomes even clearer when the ensemble averages, as estimates of the forced responses, are subtracted from the individual members of each of the two ensembles (Fig. 1b).

In the following, we compare the influence of the AMOC on air temperature within the large ensembles. We demonstrate that differences in the AMOC evolutions cause the large spread in air temperature among the members in that particular ensemble by altering both the efficiency with which the ocean takes up heat and the strength of atmospheric feedbacks. We discuss 

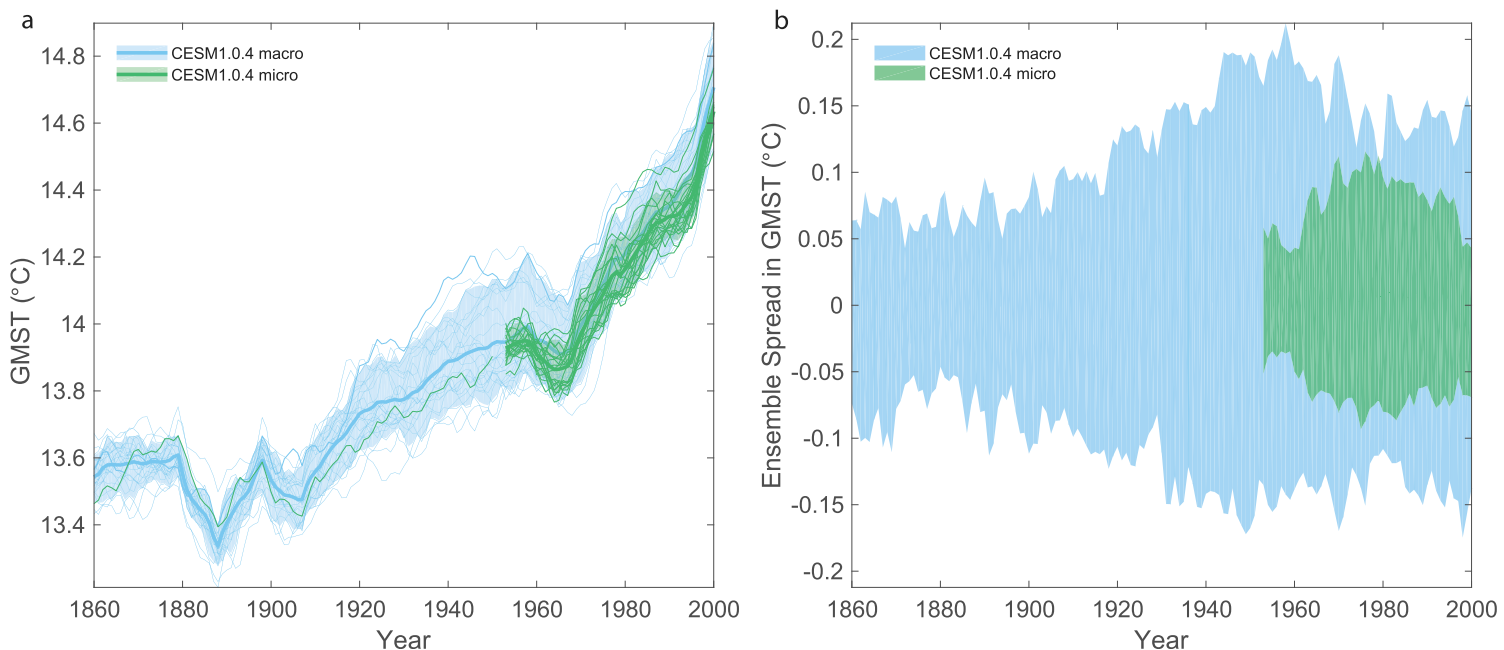

FIG. 1. (a) Comparison of two large CESM1 ensembles. Change in GMST is shown for the period 1860-2000 for CESM1.0.4 macro (blue) and for CESM1.0.4 micro (green). The thick solid lines indicate the ensemble means, and the shaded areas indicate the 10th-90thpercentile range across the ensemble members. Thin lines show the individual simulations. Every time series is smoothed with a 9-yr moving average. (b) Spread in GMST among the smoothed ensemble members (10th-90th percentile) relative to the ensemble mean for CESM1.0.4 micro (green) and macro (blue).

how AMOC variability influences the distribution of ocean heat storage vertically and among different ocean basins. We also show that AMOC-induced internal variability and the forced response add up approximately linearly within the large ensembles.

\section{Models and methods}

\section{a. Model experiments}

We analyze historical simulations spanning the period 1850-2005 from two large ensembles performed with CESM version 1.0.4. All model simulations are done with the same atmospheric resolution of $1.9^{\circ} \times 2.5^{\circ}$ using the Community Atmosphere Model, version 4 (CAM4; Neale et al. 2010), and on the same $1^{\circ}$ ocean grid using the Parallel Ocean Program 2 (POP2). CESM1 includes fully coupled atmosphere, ocean, sea ice, and land surface components (Hurrell et al. 2013). In Table 1, we summarize the two large ensembles.

We perform a 27-member ensemble (hereafter "CESM1.0.4 macro") by initializing the members from different states (at least $10 \mathrm{yr}$ apart) of a 982-yr-long preindustrial control integration, and all members are forced with the same historical radiative forcing from 1850 to 2005 (i.e., the simulation design corresponds to the historical scenario of CMIP5). Additionally, we analyze a 20-member ensemble ("CESM1.0.4 micro"), which is created by imposing small random perturbations on the atmospheric initial condition on 1 January 1950 to one run of CESM1.0.4 macro [see Fischer et al. (2013) for a full description of CESM1.0.4 micro]. The ensemble members of CESM1.0.4 micro are then forced with the same external forcings as CESM1.0.4 macro until 2004. Additionally, we branch off a second preindustrial control integration from the CESM1.0.4 control simulation, impose small random perturbations to the initial conditions, and run this control simulation in parallel to the first one for $637 \mathrm{yr}$.

We estimate the equilibrium climate sensitivity (ECS) and the effective radiative forcing to a doubling of the $\mathrm{CO}_{2}$ concentration $\left(F_{2 \times \mathrm{CO}}\right)$ of CESM1.0.4 from a simulation where the $\mathrm{CO}_{2}$ concentration is abruptly doubled and then run for $2504 \mathrm{yr}$ into quasi equilibrium [remaining top-of-atmosphere (TOA) imbalance of about $0.1 \mathrm{~W} \mathrm{~m}^{-2}$ at the end of the integration]. Using a regression approach (Gregory et al. 2004; Andrews et al. 2015), we estimate ECS as $3.1^{\circ} \mathrm{C}$ and $F_{2 \times C O 2}$ as $3.4 \mathrm{~W} \mathrm{~m}^{-2}$. With the approach of Forster et al. (2013), we then obtain a historical effective radiative forcing time series [details in supplementary material (SM) section 1].

The resolution of the CESM1 simulations is similar to that of the other models in phase 5 of the Coupled Model Intercomparison Project (CMIP5; Taylor et al.

TABLE 1. Overview of the large CESM ensembles and the control simulations used in this study. Columns show the simulation periods and the number of members.

\begin{tabular}{llc}
\hline \hline \multicolumn{1}{c}{ Ensemble } & \multicolumn{1}{c}{ Simulated years } & No. ensemble members \\
\hline CESM1.0.4 macro & $1850-2005$ & 27 \\
CESM1.0.4 micro & $1950-2004$ & 20 \\
CESM1.0.4 control & $340-1321 / 500-1136$ & 2 \\
& $(982 \mathrm{yr} / 637 \mathrm{yr})$ & \\
\end{tabular}


2012), and it is too low to account for the variability due to air-sea fluxes that arise from resolving transient eddies in the ocean (Roberts et al. 2016) and thereby might influence the representation of the overturning circulation (Winton et al. 2014). Currently, however, there is no clear evidence for a biased transient warming due to a low oceanic resolution (Winton et al. 2014).

\section{b. Methods}

We calculate annual means for all variables, and as we are interested in lower-frequency internal variability, we smooth the annual time series with a 9-yr moving average where appropriate.

To calculate ocean heat content (OHC), we multiply monthly mean ocean potential temperature in each grid cell with a constant heat capacity per unit volume $\left(c_{v}\right)$ of $4.10 \times 10^{6} \mathrm{~J} \mathrm{~m}^{-3} \mathrm{~K}^{-1}$ by assuming a constant density, $\rho=1026 \mathrm{~kg} \mathrm{~m}^{-3}$, and specific heat capacity of seawater, $c_{p}=3996 \mathrm{~J} \mathrm{~K}^{-1} \mathrm{~kg}^{-1}$. The assumption of constant $c_{v}$ introduces an uncertainty to the $\mathrm{OHC}$ of less than $3 \%$ (Hobbs et al. 2016). Then, we integrate over the depth and area of interest. We define the AMOC as the maximum of the annual mean volume streamfunction in the North Atlantic at $26.5^{\circ} \mathrm{N}$ and below $500 \mathrm{~m}$ to avoid the surface wind-driven component of the AMOC. Additionally, we evaluate the AMOC at other fixed latitudes. We only consider the Eulerian mean component of the AMOC, but including the additional components does not influence our results substantially.

From the CESM1 control integration, we find that there is only a small drift—spurious long-term trends in the simulated climate-in surface temperatures and the AMOC, but there is a significant drift in the abyssal ocean temperature, as the deep ocean is not yet in equilibrium. To account for this, we integrate ocean temperatures to different depths, and then we subtract linear trends fitted to the respective control simulation over the equivalent segments of the forced runs (using quadratic polynomials instead does not strongly influence our results). We use the same approach to remove drift from the surface heat flux and TOA imbalance to make them comparable to the drift-corrected ocean heat content.

\section{Results}

\section{a. Temperature increase and variability}

All CESM1 ensemble members simulate a general increase in GMST during the twentieth century (Fig. 1a). The various members of the same model clearly differ due to internal variability.

To quantify the role of internal variability, we subtract the ensemble mean as an estimate of the forced response and calculate the spread between the individual members of each of the two ensembles (Fig. 1b). The 10th- to 90th-percentile range among the ensemble members of CESM1.0.4 micro first increases and then remains roughly constant over the simulated period. CESM1.0.4 macro behaves differently: until around 1900, the spread among its members is comparable to the spread that CESM1.0.4 micro reaches in the late twentieth century, but then it increases markedly until 1950. Around 1950, the spread among the CESM1.0.4 macro members is approximately twice as large as for CESM1.0.4 micro. Temperatures averaged only over the Northern Hemisphere show a similar behavior.

The difference in spread among the members of the two ensembles could, in principle, arise from the approach in which the members are initialized. In SM section 2, we compare the spread of the two ensembles with a third large macro ensemble from a closely related climate model (CESM1.2.2, which includes an updated atmospheric component). This third ensemble shows a spread among its members that is approximately constant over time and similar in magnitude to that of CESM1.0.4 micro. This indicates that the timevarying and larger spread among the CESM1.0.4 macro members is not inherently related to sampling different ocean states in the macro approach of generating ensembles.

\section{b. Pattern of CESM1.0.4 macro temperature trends}

The spread among members of the CESM1.0.4 macro ensemble increases from around 1900 to 1950. Figure 2 shows the map of linear temperature trends during this period for the CESM1.0.4 macro members with the largest (Fig. 2a) and smallest (Fig. 2b) globally averaged surface air temperature increases. The globally averaged trends over this period for the two members are +0.07 and $+0.15^{\circ} \mathrm{C}$ decade $^{-1}$, respectively, while the ensemble mean trend is $+0.10^{\circ} \mathrm{C} \mathrm{decade}^{-1}$. This results in a GMST difference of $0.08^{\circ} \mathrm{C} \mathrm{decade}{ }^{-1}$, or $0.41^{\circ} \mathrm{C}$ over five decades, between these two members, which is at the upper end of what internal variability can cause on such a time scale in this model (based on the internal variability of the CESM1.0.4 piControl simulation).

Spatially, the difference in CESM1.0.4 macro temperature trends is largest in the North Atlantic (Figs. 2a,b), ranging from cooling to warming. This suggests that this region plays a key role in creating the large spread among the CESM1.0.4 macro members, as seen from Fig. 1. Temperatures increase significantly across the whole Arctic in the member with the largest GMST trend, while this warming is largely absent in the member with the smallest trend, but there is significant cooling south and east of Greenland. 

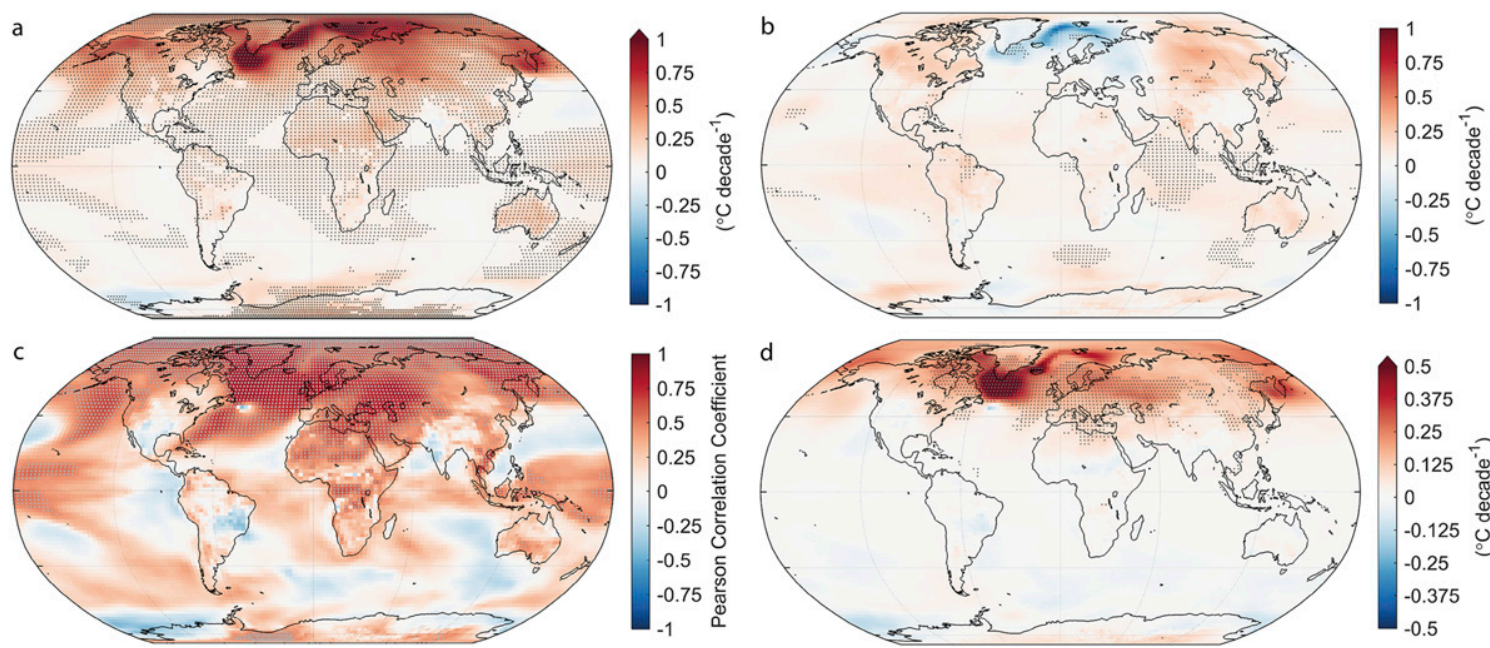

FIG. 2. Surface air temperature trends over the period 1900-50 for the CESM1.0.4 macro member with the (a) largest and (b) smallest globally averaged warming during this period. (c) The Pearson correlation coefficient between local and GMST trends across all 27 ensemble members for the same period. (d) The difference in temperature trends between a group of members with anomalously strong AMOC and weak AMOC, respectively. For (a) and (b), feasible general least squares with an AR(1) model is used to determine the slope and standard error of the trend if a Durbin-Watson test on the residuals indicates significant autocorrelation $(p \leq 0.05)$ at lag 1 . Otherwise, we use OLS on the temperatures. Then, we use two-sided Student's $t$ tests to generate local $p$ values. For (d), we use a two-sided MannWhitney $U$ test to test whether the median local trends of the two groups are equal. In all panels, stippling indicates local $p$ values small enough to satisfy the false discovery rate (FDR) criterion by Wilks (2016) with $\alpha_{\mathrm{FDR}}=0.05$.

To exclude the possibility that only these two members of the ensemble differ in their temperature evolution in the regions discussed, we calculate the local temperature trend at each grid point for each ensemble member from 1900 to 1950 and correlate these variations in the local trends with the variations in the GMST trends over the same period (Fig. 2c). This yields a spatial pattern of local surface temperature trends that are most closely related to variations in GMST from one member to the next. Significant positive correlations can be found especially over the North Atlantic $\left(0^{\circ}-60^{\circ} \mathrm{N}\right.$, $\left.5^{\circ}-75^{\circ} \mathrm{W}\right)$ and over the whole Arctic region $\left(>62.5^{\circ} \mathrm{N}\right)$, where the air temperature trends across the ensemble are well correlated with the GMST trends $(r=0.82$ and $r=0.88$, respectively). These two correlations are shown in Fig. S6 in the supplemental material. Last, we divide CESM1.0.4 macro into members with anomalous strong and weak AMOC, respectively (the significance of this will become clear in the next section), and calculate the difference in air temperature trends between the two groups. The resulting pattern again shows the largest signals in the North Atlantic and Arctic (Fig. 2d).

\section{c. AMOC in the simulations}

SST variations in the North Atlantic and, in particular, the subpolar gyre have been linked to variability in the AMOC in climate models (e.g., Delworth et al. 1993; Stouffer et al. 2006; Marshall et al. 2015; Tandon and Kushner 2015; Buckley and Marshall 2016), where a strengthening of the AMOC leads to heat convergence in the North Atlantic. Next, we explore the AMOC in CESM1 and its role in creating the CESM1.0.4 macro spread.

The mean Atlantic overturning circulation of the CESM1.0.4 piControl simulation exhibits a maximum at around $35^{\circ} \mathrm{N}$ and at a depth of approximately $950 \mathrm{~m}$ (Fig. 3a). At $26.5^{\circ} \mathrm{N}$, the control average AMOC strength is about $18 \mathrm{~Sv}\left(1 \mathrm{~Sv} \equiv 10^{6} \mathrm{~m}^{3} \mathrm{~s}^{-1}\right)$. As with the surface air temperature, the spread in simulated AMOC strength is substantially larger in CESM1.0.4 macro than in CESM1.0.4 micro (Fig. 4a): the macro members start at similar AMOC strengths, then the AMOC of some members strengthens during the twentieth century, peaks in the 1960s, and then decreases rapidly. Other members reveal a steady decrease in AMOC strength during the twentieth century, and still others show an AMOC evolution in between (Fig. 4b).

To isolate the effect of AMOC variability on the climate system, we cluster the ensemble members of CESM1.0.4 macro into two groups: a group of "strong AMOC" members that includes the eight members with the largest increase in AMOC strength between the two periods $1850-80$ and 1950-70, and a group of "weak AMOC" members containing the eight members with the largest AMOC weakening during same periods. The two groups of ensemble members start at similar mean AMOC strengths (Fig. 4b), but later, their difference in 

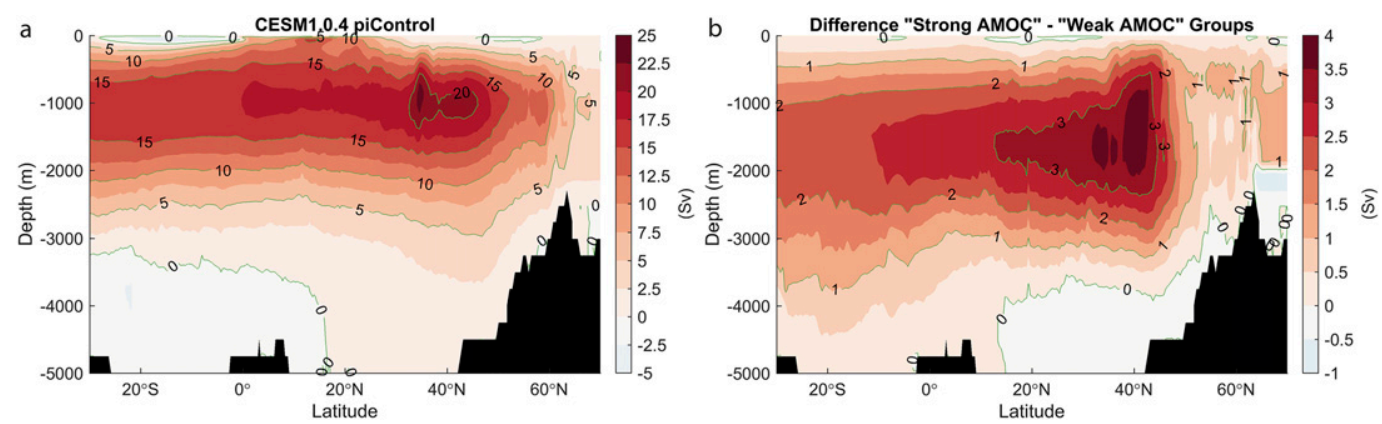

FIG. 3. Eulerian time mean AMOC streamfunctions for (a) the CESM1.0.4 piControl simulation and (b) the difference between the strong AMOC and weak AMOC members averaged over the period 1950-70.

AMOC strength reaches about $2.7 \mathrm{~Sv}$ when averaged over the period 1950-70, where the strong AMOC members display a stronger upper AMOC cell extending deeper (Fig. 3b).

To understand the cause of these differences in CESM1.0.4 macro AMOC strength, we examine the boreal winter (December-April) mean mixed layer depth (MLD) as a measure of deep convection. The control simulation shows deep-water formation in the Greenland-Iceland-Norwegian Seas, in particular in the Irminger Sea and south of Iceland, and sporadically in the Labrador Sea. CESM1 is one of the CMIP5 models with a more accurate North Atlantic deep convection (Heuzé 2017). The difference in mean winter MLD during 1950-70 between the two AMOC groups shows the largest anomalies in the Labrador Sea, south of Greenland, and south of Svalbard (Fig. 4c). Here, the strong AMOC members have a deeper mixed layer than the weak AMOC members. South of Iceland, the MLD relationship is of opposite sign. The onset of persistent deep convection in the Labrador Sea appears to be essential to the difference in AMOC strength: while the strong AMOC members show a deepening of the MLD in the central Labrador Sea after 1900, with a maximum depth of about $800 \mathrm{~m}$ around the year 1950, the weak AMOC members do not (Fig. 4d). The timing suggests the presence of deep-water formation in the Labrador Sea is crucial in setting the strength of the AMOC in the ensemble members and, thereby, causing the large spread in AMOC strength.

The importance of deep-water formation in the Labrador Sea in regulating the strength of the AMOC is confirmed by the micro ensemble: even though CESM1.0.4 micro is branched off from a member with shallow Labrador Sea MLD, in one CESM1.0.4 micro member, the central Labrador Sea MLD deepens after around 1965 (Fig. S7a). The other micro members do not indicate such an onset of persistent convection. Consequently, this particular member also simulates the strongest AMOC (Fig. S7b) and the largest GMST increase (Fig. S7c). However, as only one member simulates deep convection in the Labrador Sea, the mean AMOC is weaker for CESM1.0.4 micro than for the macro ensemble, and the spread in the AMOC and in air temperature across the members is not as strongly affected by this single member as in CESM1.0.4 macro.

Similar large trends in the AMOC also occur in the CESM1.0.4 preindustrial control integration: the AMOC increases by up to $3 \mathrm{~Sv}$, remains at an enhanced strength for around $150 \mathrm{yr}$, and then decreases again (Fig. S8). Approximately $100 \mathrm{yr}$ before the strengthening, we branch off a second control run with a micro perturbation. This second control experiment does not feature such an AMOC anomaly, confirming that random internal variability can cause this anomaly. The difference between the two control simulations shows AMOC variability that is very similar to the difference between the two groups of CESM1.0.4 macro members in terms of amplitude and duration of the AMOC anomaly (Fig. S8).

Spontaneous, unforced, large AMOC anomalies have been observed both in other climate models (Drijfhout et al. 2013) and in the model used here (Kleppin et al. 2015). Within CESM1, AMOC variability has been related to different phases of the NAO, where a strongly positive NAO phase spins up the subpolar gyre and thereby increases the salinity in the Labrador Sea (Danabasoglu et al. 2012; Kleppin et al. 2015). This initiates deep convection in the Labrador Sea, as seen in the strong AMOC members, and thereby increases AMOC strength. For further details, we refer to Kleppin et al. (2015), who study the process of switched-on/off Labrador Sea deep convection in CESM1.0.4 in detail.

It is interesting that the difference in AMOC strength among the CESM1.0.4 macro members occurs in a relatively synchronized manner and not randomly, which would be the expectation if this AMOC variability is purely due to internal variability. Possibly, the simulated climate is, at that time, in a state that enhances the 

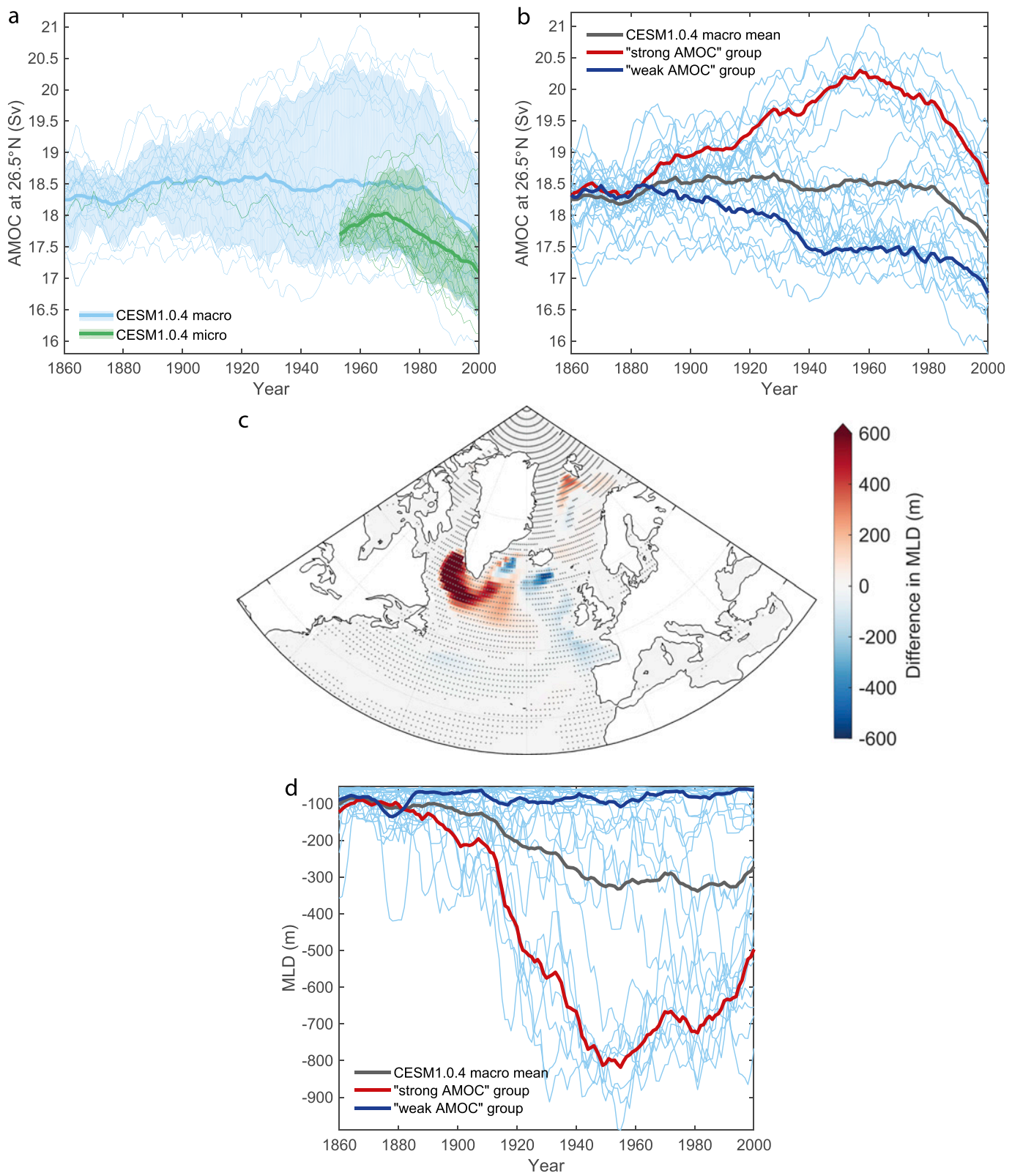

FIG. 4. (a) AMOC time series (evaluated at $26.5^{\circ} \mathrm{N}$ and below $500 \mathrm{~m}$ in the North Atlantic) for CESM1.0.4 micro (green) and macro (blue). The shaded areas indicate the 10th-90th-percentile range. (b) AMOC time series of the 27 members of CESM1.0.4 macro (thin light blue lines). The ensemble mean is shown in gray. The red line indicates the mean AMOC of the strong AMOC group and in dark blue the mean of the weak AMOC group. (c) Difference in boreal winter (December-April) MLD between strong AMOC and weak AMOC members averaged over 1950-70. Positive values indicate a deepened MLD for the strong AMOC members, compared to the weak AMOC members. We use a two-sided Mann-Whitney $U$ test to test the null hypotheses that the median MLDs of the two AMOC groups are equal. Stippling indicates local $p$ values small enough to satisfy the FDR criterion by Wilks (2016) with $\alpha_{\mathrm{FDR}}=0.05$. (d) Boreal winter mean MLD time series in the central Labrador Sea $\left(57^{\circ}-64^{\circ} \mathrm{N}, 50.5^{\circ}-56.5^{\circ} \mathrm{W}\right)$ for the 27 ensemble members (thin light blue lines) of CESM1.0.4 macro. The red line indicates the mean MLD of the strong AMOC group, and dark blue indicates the mean of the weak AMOC group. Each time series has been smoothed with a 9-yr moving average.

probability for such large AMOC anomalies within the model (Kleppin et al. 2015), potentially triggered by the Krakatau volcanic eruption in 1883 (Ding et al. 2014). With stronger anthropogenic warming, the model might leave a climate regime that favors persistent deep-water formation in the Labrador Sea, and only one out of 20 members of CESM1.0.4 micro simulates an enhanced AMOC. This is, however, beyond the scope of this work, 

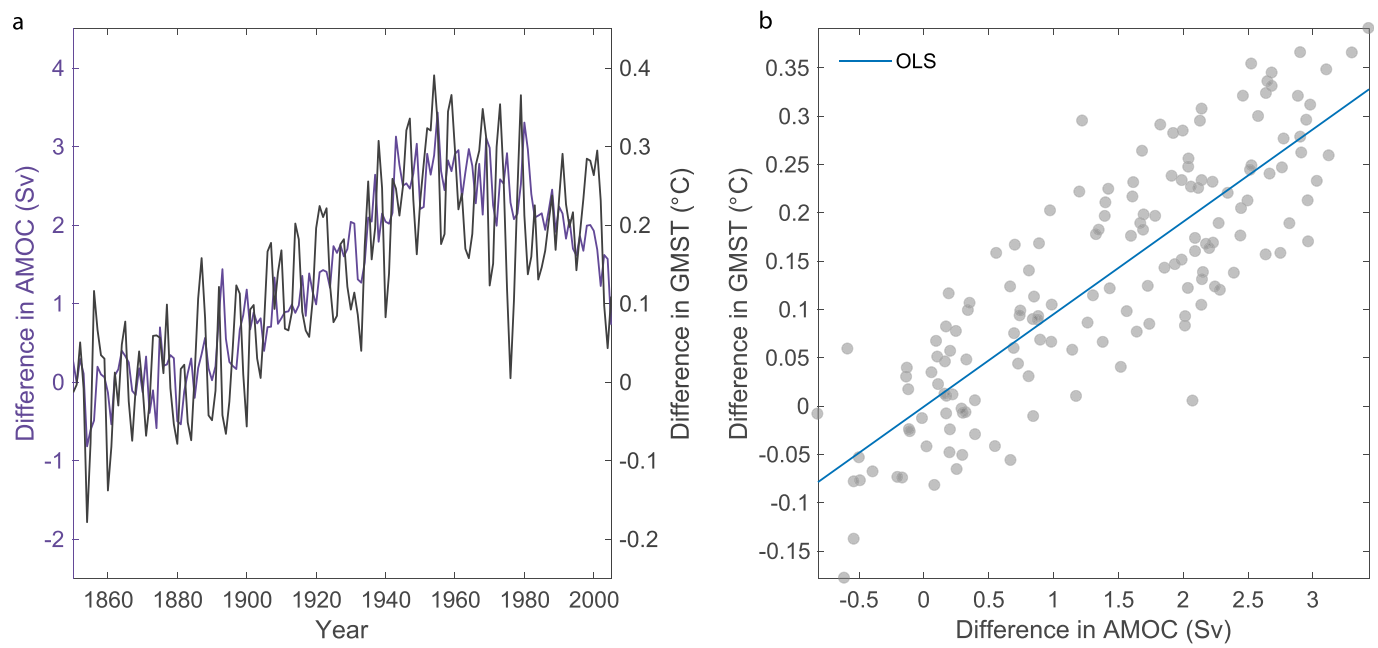

FIG. 5. (a) Difference in AMOC and GMST for the members of the strong and weak AMOC groups of CESM1.0.4 macro over the simulated period. (b) The differences in AMOC and GMST plotted against each other with AMOC lagging by $1 \mathrm{yr}$ (gray dots) together with the OLS regression.

and the results are also very likely to be strongly model dependent.

\section{d. Sensitivity of air temperatures to AMOC variability}

Both Marini and Frankignoul (2014) and Tandon and Kushner (2015) demonstrate that the AMOC generally leads North Atlantic SSTs in climate models when the AMOC is defined as the maximum in the streamfunction in the whole North Atlantic. This is also the case for an earlier version of the model we use here (Danabasoglu et al. 2012). Using the two CESM1 control integrations, we find that the lead-lag correlation between annual North Atlantic surface air temperature and annual AMOC reaches a maximum when the AMOC at $50^{\circ} \mathrm{N}$ leads by $1 \mathrm{yr}$. Consistent with a southward propagation of the AMOC signal (Zhang 2010), the AMOC lags the North Atlantic air temperatures by $1 \mathrm{yr}$ at $26.5^{\circ} \mathrm{N}$ in each of the two control integrations.

To quantify how strongly AMOC variations at $26.5^{\circ} \mathrm{N}$ influence air temperatures on a multidecadal time scale, we calculate the difference in annual GMST and in annual AMOC strength for the two groups of CESM1.0.4 macro members (Fig. 5a) and regress the surface air temperature difference on the AMOC difference at the lag that maximizes the cross correlation using ordinary least squares (OLS). As a potential limitation of the OLS, the presence of intrinsic scatter in both the dependent and independent variables leads to an underestimation of the regression slope, known as "regression dilution" (Frost and Thompson 2000). We therefore interpret the OLS as a lower estimate of the slope and test the robustness of the OLS regression by a number of alternative regression approaches (discussed in SM section 3). By averaging across the ensemble members, a large fraction of the interannual variability has been removed, and our results are not crucially dependent on the regression approach. In the following, we stick to OLS.

There is a strong correlation between the AMOC and GMST ( $r=0.84$ on the annual means and when the AMOC at $26.5^{\circ} \mathrm{N}$ lags by $1 \mathrm{yr}$ ). OLS regression between changes in the AMOC and changes in global temperatures results in a slope of $0.10^{\circ} \mathrm{CSv}^{-1}$ (Fig. 5b). For the Northern Hemisphere, we find a higher correlation of $r=0.90$ and an OLS sensitivity, $\Delta T / \Delta \mathrm{AMOC}$, of $0.17^{\circ} \mathrm{CSv}^{-1}$. In Table 2, we list the estimated correlations and sensitivities and report the range of sensitivities obtained with the various methods.

As a second independent estimate, we regress the AMOC strength and surface air temperature of the two CESM1.0.4 control simulations against each other. These $\Delta T / \triangle \mathrm{AMOC}$ estimates are consistent with our previous results, suggesting robustness independent of whether $\Delta T / \Delta \mathrm{AMOC}$ is derived from forced or control simulations and that the AMOC-induced air temperature variability superimposes linearly onto the forced response. Additionally, we smooth the AMOC and air temperature time series before the regression to suppress high-frequency variability and find that while this improves the correlation between the two, the slope is not strongly influenced (Fig. S5).

In Table 2, we compare the sensitivities with other studies. Both Knight et al. (2005) and Zhang et al. (2007) find weaker sensitivities. Besides model difference (both 
TABLE 2. Estimates of global and Northern Hemisphere mean surface air temperature sensitivity to changes in AMOC strength from OLS regression. The values in brackets indicate the range from the alternative slope estimation procedures (see SM section 3). Additionally, the Pearson correlation coefficient between annual AMOC and annual surface temperatures (at lag with highest correlation: 1-yr lag in all cases) is reported. All reported correlation coefficients for the control simulations are significant $(p<0.01)$. We correct for autocorrelation in the time series by adjusting the degrees of freedom. Therefore, we estimate the effective sample size $N_{\text {eff }}$ as $N_{\text {eff }}=N /\left[1+2 \sum_{i=1}^{10 \cdot \log _{10}(N)} \rho_{\text {AMOC }}(i) \rho_{\mathrm{SAT}}(i)\right]$, where $N$ is the length of the control simulation and $\rho_{\mathrm{AMOC}}$ and $\rho_{\mathrm{SAT}}$ are the sample autocorrelations of the AMOC and surface air temperature time series at lag $i$, respectively (Livezey and Chen 1983). We calculate the significance with a Student's $t$ test using $N_{\text {eff }}-2$ degrees of freedom. The table further lists information on the model(s) and the type of experiments used.

\begin{tabular}{|c|c|c|c|c|c|c|}
\hline Study & Model & $\begin{array}{l}\text { AMOC } \\
\text { definition }\end{array}$ & $\begin{array}{c}\text { Global } \\
\left({ }^{\circ} \mathrm{C} \mathrm{Sv}^{-1}\right) \\
\text { sensitivity }\end{array}$ & $\begin{array}{l}\text { Northern } \\
\text { Hemisphere } \\
\left({ }^{\circ} \mathrm{C} \mathrm{Sv}^{-1}\right) \\
\text { sensitivity }\end{array}$ & $\begin{array}{l}\text { Correlation } \\
\text { (AMOC with } \\
\text { global/NH } \\
\text { temperatures) }\end{array}$ & Type of experiment \\
\hline \multirow[t]{4}{*}{ This study } & CESM1.0.4 & $\begin{array}{l}26.5^{\circ} \mathrm{N} \text { and } \\
\text { below } 500 \mathrm{~m}\end{array}$ & $0.10(0.09-0.12)$ & $0.17(0.17-0.19)$ & $0.84 / 0.90$ & $\begin{array}{l}\text { Large ensemble of historical } \\
\text { simulations (difference between } \\
\text { two groups of members) }\end{array}$ \\
\hline & & & $0.10(0.10-0.18)$ & $0.16(0.16-0.24)$ & $0.64 / 0.70$ & $\begin{array}{l}\text { First CESM1.0.4 control } \\
\text { integration }(982 \mathrm{yr})\end{array}$ \\
\hline & & & $0.10(0.11-0.23)$ & $0.13(0.14-0.29)$ & $0.53 / 0.54$ & $\begin{array}{l}\text { Second CESM1.0.4 control } \\
\text { integration }(637 \mathrm{yr})\end{array}$ \\
\hline & & & $0.10(0.10-0.17)$ & $0.16(0.16-0.23)$ & $0.65 / 0.71$ & $\begin{array}{l}\text { Difference between CESM1.0.4 } \\
\text { control integrations }\end{array}$ \\
\hline Knight et al. (2005) & HadCM3 & $30^{\circ} \mathrm{N}$ & $0.05 \pm 0.02$ & $0.09 \pm 0.02$ & l & Control integration (1400 yr) \\
\hline Zhang et al. (2007) & GFDL CM2.1 & 1 & l & $\begin{array}{l}0.05 \pm 0.02 \\
\text { (one standard } \\
\text { deviation) }\end{array}$ & l & $\begin{array}{l}\text { Assimilation (prescribing heat } \\
\text { flux over North Atlantic) }\end{array}$ \\
\hline
\end{tabular}

the climate and statistical models), if and how the time series are smoothed, as well as the latitude where AMOC is quantified, matters for these sensitivities since AMOC variability varies with the latitude and reaches a maximum at around $45^{\circ} \mathrm{N}$ in most climate models (Muir and Fedorov 2017), possibly explaining part of the difference in the found sensitivities.

\section{e. How does the AMOC control multidecadal air temperature trends in CESM1.0.4 macro?}

Focusing on the period 1950-70, when the difference in the AMOC of CESM1.0.4 macro is largest (Fig. 4b), we first examine the zonal mean ocean temperature change (compared to the preindustrial period 1850-80). For the strong AMOC members with increased deep-water formation, more heat is injected into the deep ocean, which can be seen most clearly at around $60^{\circ} \mathrm{N}$, compared to the weak AMOC members (Fig. 6a). Hence, the strong AMOC members show warming in the deep ocean below about $2500 \mathrm{~m}$ (in the following, referred to as abyssal ocean), while this warming is largely absent in the weak AMOC members due to missing Labrador Sea ventilation (Fig. 6b). With warmer North Atlantic subpolar SSTs for the strong AMOC members, however, more heat is also lost to the atmosphere (Fig. 6d), resulting in a net heat loss in the Northern Hemisphere high-latitude ocean for the strong AMOC members, while the weak
AMOC members show net heat uptake there. The increased heat loss observed in the strong AMOC group occurs mainly through the Labrador Sea and Arctic Ocean (Fig. 7a; Fig. S9 shows the boundaries of the ocean basins). This is in agreement with findings from other climate models (Rugenstein et al. 2013; Winton et al. 2013). Despite the enhanced heat loss, more heat is stored in the high-latitude ocean for the strong AMOC members (Fig. 6e). Northward heat transport intensifies together with a strengthened AMOC (Fig. 6f), thereby exporting heat from the lower latitudes to the higher northern latitudes. Consequently, less heat is stored at intermediate depths (from 300 to $2000 \mathrm{~m}$ ) in the lower-latitude ocean from around $40^{\circ} \mathrm{S}$ to $40^{\circ} \mathrm{N}$ (Fig. $6 \mathrm{c}$ ).

For the weak AMOC members, the anomalous ocean heat transport is reversed (Fig. 6f), and relatively more of the heat is stored at lower latitudes (Fig. 6e). This is consistent with the equatorward redistribution of existing heat meridionally from the high northern latitudes described by Xie and Vallis (2012) as a response to an AMOC weakening.

Although the large heat loss of the strong AMOC group in the high-latitude ocean is partly compensated by increased heat uptake by the Pacific and Atlantic Oceans (Fig. 7a; the Labrador Sea is not included in the Atlantic), the overall heat uptake decreases when the AMOC strengthens (Fig. 7a). 

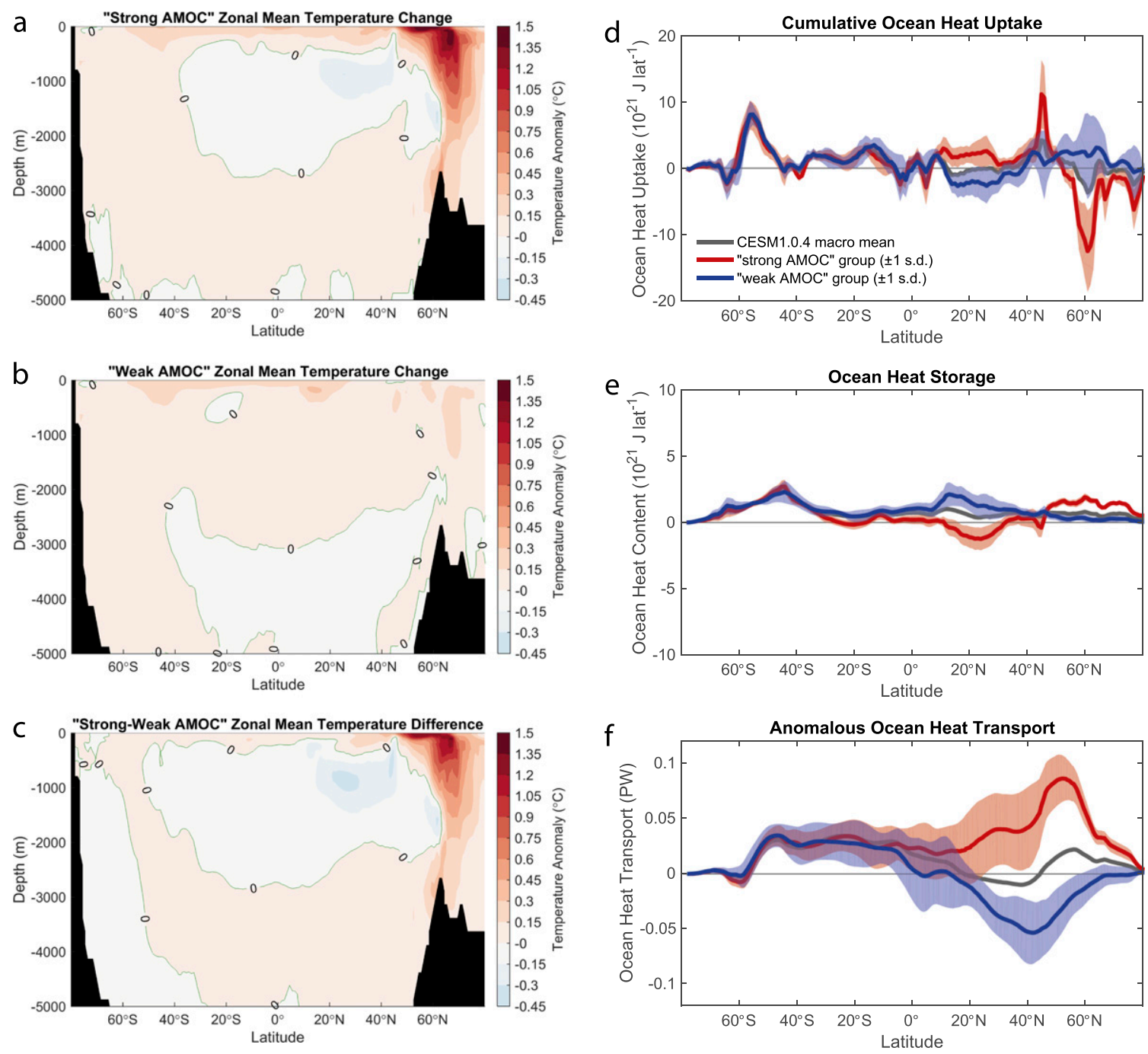

FIG. 6. (a)-(c) The zonal mean ocean temperature change averaged over the period 1950-70 with respect to the preindustrial period 1850-80 for the strong AMOC members, the weak AMOC members, and the difference between the two, respectively. (d) The cumulative zonal mean ocean heat uptake (positive: heat is taken up; negative: heat is released), (e) the zonal mean heat storage, and (f) the anomalous global ocean heat transport for the difference between the two periods. The shading in (d)-(f) indicates the \pm 1 standard deviation range across the members of each group.

Accordingly, the globally averaged $\mathrm{OHC}$ decreases when the AMOC strengthens relative to an AMOC weakening, and vice versa (Fig. 7b). The difference between the two CESM1.0.4 control simulations confirms this (Fig. S10). The macro ensemble mean $\mathrm{OHC}$ increases by $40.4 \pm 5.0 \times 10^{22} \mathrm{~J}$ over the full water column between the two periods 1995-2005 and 1850-80 (we report \pm 1 standard deviations across the ensemble members). For the strong AMOC group, it is only $34.8 \pm$ $3.0 \times 10^{22} \mathrm{~J}$, while the weak AMOC group simulates a mean $\mathrm{OHC}$ increase of $44.1 \pm 4.8 \times 10^{22} \mathrm{~J}$ (Fig. $7 \mathrm{c}$ ). Most of the additional heat in the weak AMOC members, which mainly occurs through reduced heat loss in the Labrador Sea, can be found in the Atlantic Ocean
(Fig. 7d). While for the ensemble mean, $7.7 \pm 3.3 \times 10^{22} \mathrm{~J}$ of the heat is stored in the Atlantic Ocean $(19 \pm 7 \%$ of the total amount of heat taken up), it is $10.9 \pm 2.0 \times 10^{22} \mathrm{~J}$ for the weak AMOC members $(25 \pm 3 \%)$, but only $3.9 \pm$ $1.3 \times 10^{22} \mathrm{~J}$ for the strong AMOC group (11 $\left.\pm 5 \%\right)$.

With a time lag of several decades, in addition to the reduced OHC storage in the Atlantic, less heat is stored in the Pacific Ocean within the members simulating a strong AMOC. compared to the ensemble mean (Fig. 7e). The difference between the two CESM1.0.4 control runs shows a qualitatively similar signal in the Pacific (Fig. S10). This signal may seem surprising, given the increased surface heat flux into the Pacific Ocean when the AMOC strength is enhanced (Fig. 7a), but it 

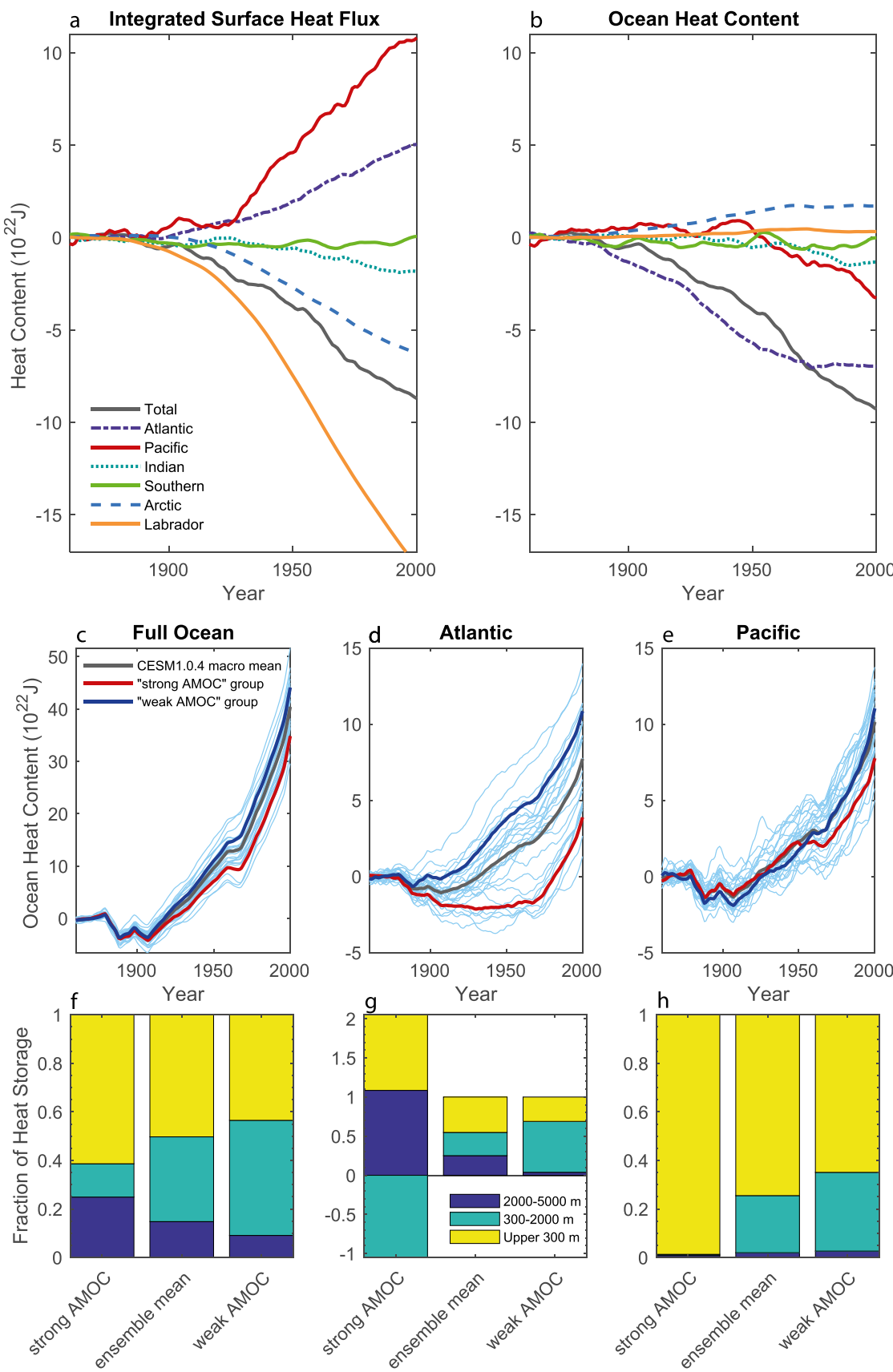

FIG. 7. (a) Difference in integrated net heat flux into different ocean basins among ensemble members of the two groups of strong and weak AMOC. Positive values indicate a larger net heat uptake by the ocean in the strong AMOC members, compared to the weak AMOC members. (b) Difference in ocean heat content in the ocean basins (boundaries of the ocean basins are shown in Fig. S9). Positive values indicate that the ocean heat storage is larger for the strong AMOC members, compared to the weak AMOC members. The differences between (a) and (b) are mainly due to transport processes. (c)-(e) The ocean heat content anomaly for the 27 ensemble members (light blue lines) integrated over the whole ocean depth for the World Ocean, the Atlantic, and the Pacific, respectively, and with respect to the reference period 1850-80. All time series are smoothed with a 9-yr moving average. (f)-(h) The fraction of ocean heat stored in the upper $300 \mathrm{~m}$ (yellow), from 300 to $2000 \mathrm{~m}$ (green), and from 2000 to $5000 \mathrm{~m}$ (blue) for the same regions is shown for the ensemble mean and the two groups of ensemble members (the sum of all fractions is 1 in each case, but individual components might exceed 1 if there is cooling at some depths). We calculate the $\mathrm{OHC}$ change for the three depth ranges as the difference between the two periods 1995-2005 and 1850-80. 
can be understood in terms of a heat redistribution: there is an overall strengthening of the global circulation, with more heat being taken up by and exported out of the Pacific Ocean (Garuba and Klinger 2016). In total, this results in a decreased storage of heat in the Pacific when the AMOC is strong.

Variations in the AMOC not only cause a redistribution of heat within the ocean basins and a net change in total heat storage, but also influence the vertical distribution of heat. Xie and Vallis (2012) find in the case of a weakening of the AMOC, there is a redistribution of existing heat from the upper ocean to the deeper ocean (from the upper $400 \mathrm{~m}$ mainly to the 400-1400-m depth range in their simulations). Banks and Gregory (2006) related this to reduced cold upwelling in the low latitudes of the Atlantic and thereby warming in the deeper layers. Consistent with this mechanism, we find that the upper $300 \mathrm{~m}$ of the World Ocean warms more in the case of a strong AMOC. Together with the overall reduced heat storage under a strengthening AMOC, a larger fraction of the heat anomaly can be found near the surface in the strong AMOC group. For these members, on average, $61 \pm 6 \%$ of the heat taken up during the twentieth century is located in the upper $300 \mathrm{~m}$ of the global ocean, while it is only $43 \pm 3 \%$ for the weak AMOC members (Figs. 7f, 6c). For the ensemble mean, around half of the heat taken up is stored in the upper $300 \mathrm{~m}$ of the World Ocean. For the weak AMOC members, the intermediate ocean becomes a region where a significant part of the heat anomaly is stored (on average, $47 \pm 6 \%$ of the total heat storage anomaly), while this depth range only warms slightly for the strong AMOC members (on average, $14 \pm 8 \%$ of the excess heat taken up can be found in this depth range). In the abyssal ocean, below a depth of $2000 \mathrm{~m}$, this is again reversed: associated with the increased export of heat with the increased deep-water formation and the overall reduced heat storage, a larger fraction of the heat anomaly can be found at these depths for the strong AMOC members $(25 \pm 3 \%)$ than for the weak AMOC members $(9 \pm$ $4 \%)$. Again, the difference between two CESM1.0.4 control integrations confirms this pattern (Fig. S11), demonstrating that the AMOC-induced $\mathrm{OHC}$ variability superimposes approximately linearly onto the greenhouse gas-forced global OHC increase for different depth ranges.

To put this AMOC-induced $\mathrm{OHC}$ variability into perspective, we compare the twentieth-century global OHC increase simulated by CESM1.0.4 macro with a set of 20 CMIP5 models. For both depth ranges of 300-2000 and $2000-5000 \mathrm{~m}$, the spread among the CESM1.0.4 macro members is comparable to the spread among the
CMIP5 models throughout the twentieth century, except for two CMIP5 models that deviate substantially from the ensemble (Fig. S12). The interquartile range among the CESM1.0.4 macro members is roughly onethird $\left(6.9 \times 10^{22} \mathrm{~J}\right)$ of that of the CMIP5 ensemble $\left(20.3 \times 10^{22} \mathrm{~J}\right)$ for the overall twentieth-century OHC change over the full depth (1995-2005 vs preindustrial period). Hence, while still noteworthy, the fraction of the CMIP5 spread that can potentially be explained by internal variability is less for the full ocean than the two depth ranges in the deeper ocean. The reason for this is twofold: first, the change in OHC of the top $300 \mathrm{~m}$, which contributes substantially to the overall additional heat storage, is dominated by differences in the model physics. Second, the enhanced warming in the 300-2000-m depth range in the weak AMOC members is partly compensated by their reduced warming below $2000 \mathrm{~m}$, compared to the strong AMOC group.

To quantify the effect of the altered heat uptake on global temperatures, we use the concept of ocean heat uptake efficiency, $\kappa=N / \Delta T$, where $N$ is the TOA radiative imbalance that is closely related to the ocean heat uptake, since nearly all of the added heat is stored in the ocean, and $\Delta T$ is the GMST change (Gregory and Mitchell 1997; Raper et al. 2002). A larger efficiency suppresses the transient surface temperature increase by sequestering heat more effectively into the deeper ocean. For our simulations, the radiative forcing is not monotonically increasing, but after volcanic eruptions, the forcing drops quickly, potentially limiting the usefulness of the heat uptake efficiency concept (Raper et al. 2002). To mitigate this issue, we calculate $\kappa$ by using 30-yr-long moving averages of $N$ and $\Delta T$ with respect to the preindustrial control integration. Further, we are mainly interested in how $\kappa$ differs among the ensemble members that are equally influenced by volcanic forcing and less in its absolute value. The ocean heat uptake efficiency $\kappa$ is consistently larger for the weak AMOC members than for the strong AMOC group (Fig. 8a; the first value is for the 30 -yr period centered at 1930 since the signals in $N$ and $\Delta T$ are too small to calculate a meaningful $\kappa$ for earlier periods). Toward the end of the twentieth century, when the AMOC strength of the two groups converges, their $\kappa$ values converge as well.

To examine whether the difference in $\kappa$ fully explains the difference in GMST between the two groups of ensemble members, we use a global linearized energy balance approach (Gregory et al. 2004):

$$
N=F_{\text {hist }}-\lambda \Delta T \approx \kappa \Delta T .
$$

Here, $N$ is split between the effective historical radiative forcing $\left(F_{\text {hist }}\right)$ and energy escaping to space $(\lambda \Delta T)$, 

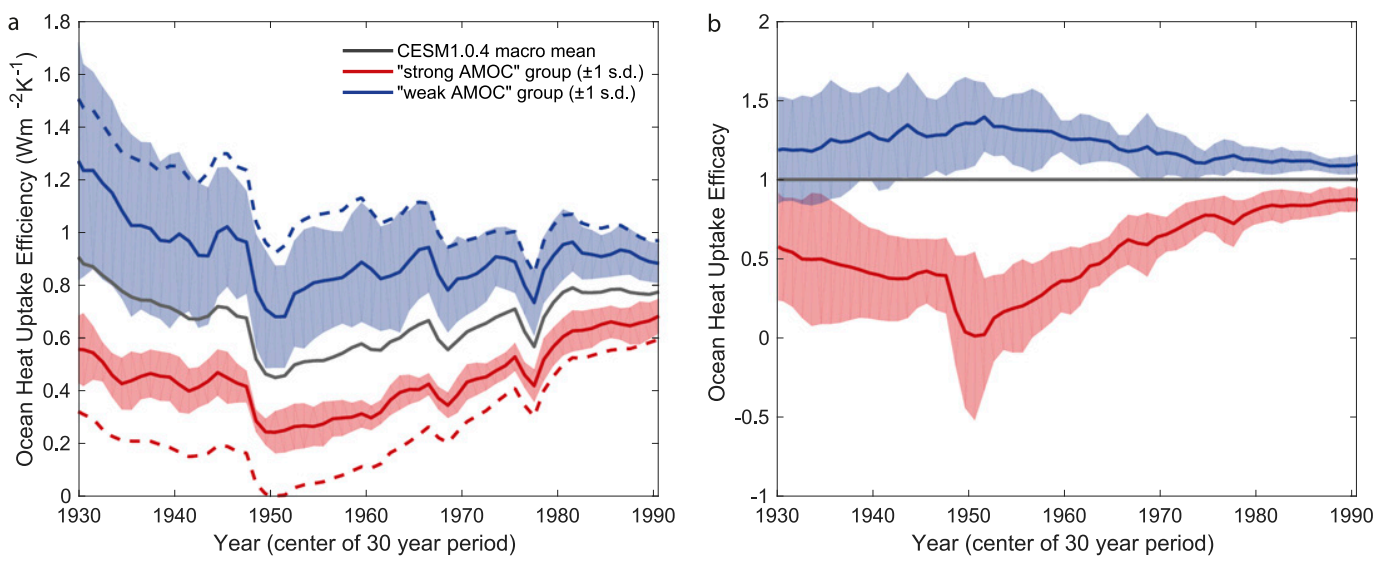

FIG. 8. (a) The ocean heat uptake efficiency $\kappa$ for the CESM1.0.4 macro ensemble mean (gray) and for the two groups of strong (red) and weak (blue) AMOC, respectively. Efficiency $\kappa$ is calculated using 30-yr-long moving averages. The dashed lines indicate theoretical heat uptake efficiencies obtained by rearranging Eq. (1) (for the ensemble mean the theoretical $\kappa$ is equal to the actual $\kappa$ ). (b) The temporal evolution of the heat uptake efficacy $\varepsilon$. The ensemble mean $\varepsilon=1$ because of the used method to evaluate the historical radiative forcing. The shading indicates the \pm 1 standard deviation range across the members of each group.

where $\lambda$ is the global net climate feedback parameter $\left(\lambda=F_{2 \times \mathrm{CO}_{2}} / \mathrm{ECS}\right)$, which encompasses the various feedback processes in the climate system. In a first step, we estimate $F_{\text {hist }}$ using $\lambda$ from the CESM1.0.4 $2 \mathrm{xCO}_{2}$ simulation (cf. Forster et al. 2013; details in SM section 1). In a second step, we calculate a theoretical $\kappa$ from rearranging Eq. (1). If the difference in $\kappa$ alone explains the difference in $\Delta T$ between the two groups of ensemble members, the theoretical $\kappa$ values of the strong AMOC and weak AMOC groups and their actual values would be the same. This is, however, not the case, and the theoretical $\kappa$ values (dashed lines in Fig. 8a) are farther apart than the actual heat uptake efficiencies. Accordingly, the increased heat uptake efficiency of the weak AMOC members explains part of the difference in GMST between the two groups, but not the full behavior.

Winton et al. (2010) introduced the ocean heat uptake efficacy $\varepsilon$ that is attached to the heat uptake $N$ and relates the amount of ocean heat uptake required to mitigate a specific amount of well-mixed greenhouse gas-induced warming (Rose and Rayborn 2016). If $\varepsilon>1$, the same amount of heat taken up has a larger cooling effect on the climate (i.e., can offset more greenhouse gas-induced warming) than for $\varepsilon \leq 1$. In our case, $\varepsilon=1$ by definition for the CESM1.0.4 macro ensemble mean because we derived the historical radiative forcing with this assumption. However, again, we are interested in how the individual members deviate from the ensemble mean; therefore, this limitation is not critical. The weak AMOC members show an increased $\varepsilon$, compared to the strong AMOC members, and the maximum difference is reached when the difference in AMOC is largest, and then, similar to $\kappa, \varepsilon$ of the two groups converges toward the end of the twentieth century (Fig. 8b). Several studies linked an increased heat uptake at high latitudes to an enhanced efficacy, both with idealized (Kang and Xie 2014; Rose et al. 2014; Rugenstein et al. 2016) and realistic heat uptake patterns (Rugenstein et al. 2016; Trossman et al. 2016; Garuba et al. 2018; He et al. 2017).

The high efficacy of high-latitude ocean heat uptake has been attributed to the sensitive local feedbacks at these latitudes that are activated by the temperature pattern induced by the heat uptake (Haugstad et al. 2017). To explain the larger heat uptake efficacy of the weak AMOC members, we decompose $\lambda$ into allsky shortwave $\left(\lambda_{\mathrm{SW}}\right)$ and longwave $\left(\lambda_{\mathrm{LW}}\right)$ feedbacks (Forster and Taylor 2006). Because of the potentially large "cloud masking" bias (Soden et al. 2004), we do not further split up the feedbacks into clear-sky and cloud forcing components. In the midtwentieth century, $\lambda_{\mathrm{LW}}$ contributes around two-thirds of the difference in $\lambda$ (Fig. S2). Parameter $\lambda_{\mathrm{LW}}$ incorporates the Planck, water vapor, and lapse rate feedbacks, which are all unlikely to change substantially under a realistic shift in the ocean heat uptake patterns (Rugenstein et al. 2016; He et al. 2017). Hence, it is likely that the longwave cloud feedback contributes to the change in $\lambda_{\mathrm{LW}}$, which is consistent with the results of Rugenstein et al. (2016), who used the same atmospheric model, coupled to a slab ocean and forced with different heat uptake patterns. Parameter $\lambda_{\mathrm{Sw}}$ includes the shortwave cloud feedback, sea ice/snow feedback, and the shortwave absorption of water vapor. The sea ice feedback has been shown to be climate state dependent (e.g., Colman and McAvaney 2009). The weak AMOC group shows an enhanced Arctic sea 
ice area, compared to the strong AMOC members (Fig. S13e), and it, therefore, likely contributes to the difference in $\lambda_{\text {SW }}$ (Garuba et al. 2018). Shortwave cloud feedbacks have been identified as one of the key factors to explain the larger efficacy of high-latitude ocean heat uptake (Rose et al. 2014; Rose and Rayborn 2016; Trossman et al. 2016). Over the eastern North Atlantic, the low cloud coverage (cloud-top pressure $>700 \mathrm{hPa}$ ) increases for the weak AMOC members, compared to the strong AMOC group, which leads to an increased planetary albedo over this region (Fig. S13c), consistent with Zhang et al. (2010) and Trossman et al. (2016). There are, however, also decreases in the low cloud coverage over the sea ice edge and the Labrador Sea. With this approach, an exact decomposition into the individual feedbacks cannot be achieved, but we conclude from the analysis above that the increased heat uptake efficacy of the weak AMOC members is consistent with a contribution from cloud and albedo feedbacks.

\section{Discussion and conclusions}

In this study, we examine two large CESM1 ensembles. The spread in the decadally smoothed GMST across ensemble members of CESM1.0.4 macro varies over time and is up to about twice as large as for CESM1.0.4 micro. We show that this behavior does not depend on how the ensemble is generated-whether by small random perturbations (micro) or by branching off the members from different states of a control integration (macro) - but can be attributed to differing trends in the AMOC in this ensemble. Some of the ensemble members show an increasing AMOC strength in the twentieth century, while others simulate a weakening. The members with a strong AMOC simulate an onset of persistent deep convection in the Labrador Sea that reaches a maximum in the midtwentieth century, while the members with weaker AMOC do not show continuous deep-water formation in this region.

Variations in the AMOC are efficient in modulating Northern Hemisphere and even global surface air temperatures in CESM1.0.4 and might, therefore, amplify or dampen temperature trends on multidecadal time scales. We estimate a sensitivity of about 0.09$0.12^{\circ} \mathrm{CSv}^{-1}$ for global mean and of about 0.17 $0.19^{\circ} \mathrm{CSv}^{-1}$ for Northern Hemisphere mean surface temperatures to the AMOC variability at $26.5^{\circ} \mathrm{N}$ for CESM1.0.4 macro on multidecadal time scales. The hypothesis that the AMOC-related internal variability superimposes approximately linearly onto the forced response is supported by a similar sensitivity when we estimate these values from the CESM1.0.4 control integrations.

The large sensitivity of surface air temperature to AMOC variability can be mainly attributed to two factors. First, a strengthening of the AMOC leads to increased heat loss in the North Atlantic and to a decrease in overall ocean heat storage, compared to a weakening of the AMOC. Therefore, ocean heat uptake efficiency is reduced when the AMOC strengthens, and, accordingly, the surface air temperature increase is less dampened by ocean heat uptake (Rugenstein et al. 2013; Watanabe et al. 2013; Winton et al. 2014).

Second, the increased heat loss in the North Atlantic following a positive AMOC anomaly leads to a decreased ocean heat uptake efficacy (Winton et al. 2013) by shifting the heat uptake pattern into a region with weaker feedbacks. Accordingly, the cooling influence of $1 \mathrm{~W} \mathrm{~m}^{-2}$ heat taken up by the ocean is larger for the weak AMOC than for the strong AMOC members. Temporal variations in the efficacy have already been observed by Paynter and Frölicher (2015), but here, we can tie such variations in CESM1.0.4 macro to variability in the AMOC and the associated high-latitude heat uptake. Both cloud and sea ice feedbacks likely contribute to the increased efficacy with weakening AMOC.

Kostov et al. (2014) offered a different perspective, according to which the climatological mean AMOC controls the heat storage, where models with stronger and deeper AMOC export a larger fraction of the heat taken up into the deep ocean. We cannot dismiss the role of the climatological mean AMOC on ocean heat uptake, but we are able to isolate the role of AMOC trends on ocean heat storage, since all CESM1.0.4 macro ensemble members are initialized from a similar background AMOC. Our results support the mechanism of Winton et al. (2013) and Rugenstein et al. (2013), according to which AMOC anomalies exert a strong influence on large-scale surface air temperature mainly by altering high-latitude ocean heat uptake.

The CESM1.0.4 macro members show a spread in twentieth-century ocean heat storage for depth ranges from 300 to $2000 \mathrm{~m}$ and from 2000 to $5000 \mathrm{~m}$ that is comparable to that of a set of CMIP5 models (Fig. S12). Further, AMOC trends influence the partitioning of heat between upper and deeper ocean and among the different ocean basins (Banks and Gregory 2006; Xie and Vallis 2012; Garuba and Klinger 2016). The CMIP5 models simulate differing trends in the AMOC during the twentieth century and differ in their future projected decrease (Cheng et al. 2013). Long-term AMOC reconstructions show conflicting results, and, potentially, 
the AMOC has already slowed down during the twentieth century (Rahmstorf et al. 2015). Our results indicate, in agreement with earlier findings (Winton et al. 2014; Trossman et al. 2016; He et al. 2017), that multidecadal trends in the AMOC could have important implications for the intercomparison of climate models and between climate models and observations, as AMOC-related internal variability may contribute significantly to GMST, deep-ocean heat storage trends, and the partitioning of stored heat among different ocean basins on a multidecadal time scale. Different to the deeper ocean, the spread in the upper 300-m ocean heat storage across the CESM1.0.4 macro ensemble members is relatively small compared to the CMIP5 spread, indicating that differences in the model physics largely determine the upper-ocean heat storage. Also, the heat uptake in the Southern Ocean, the region where most of the heat is taken up for the CMIP5 ensemble (Frölicher et al. 2015), is not significantly influenced in CESM1.0.4 by differing AMOC trends. Finally, different models might react with different sensitivities to AMOC changes (Schmith et al. 2014). Nonetheless, long-term observations of the AMOC are vital to better understand and quantify multidecadal AMOC variability and how it might impact Earth's climate.

Acknowledgments. The CESM1 simulation data are available upon email request to the corresponding author. We thank Urs Beyerle for performing the CESM1 experiments, and we are grateful to the three anonymous reviewers for their thoughtful comments.

We acknowledge the World Climate Research Programme's Working Group on Coupled Modelling, which is responsible for CMIP, and we thank the climate modeling groups for producing and making available their model output. For CMIP, the U.S. Department of Energy's Program for Climate Model Diagnosis and Intercomparison provides coordinating support and led development of software infrastructure in partnership with the Global Organization for Earth System Science Portals.

\section{REFERENCES}

Andrews, T., J. M. Gregory, and M. J. Webb, 2015: The dependence of radiative forcing and feedback on evolving patterns of surface temperature change in climate models. J. Climate, 28, 1630-1648, https://doi.org/10.1175/JCLI-D-14-00545.1.

Banks, H. T., and J. M. Gregory, 2006: Mechanisms of ocean heat uptake in a coupled climate model and the implications for tracer based predictions of ocean heat uptake. Geophys. Res. Lett., 33, L07608, https://doi.org/10.1029/2005GL025352.

Brown, P. T., W. H. Li, J. H. Jiang, and H. Su, 2016: Spread in the magnitude of climate model interdecadal global temperature variability traced to disagreements over high-latitude oceans. Geophys. Res. Lett., 43, 12 543-12 549, https://doi.org/10.1002/ 2016 GL071442.

Buckley, M. W., and J. Marshall, 2016: Observations, inferences, and mechanisms of the Atlantic meridional overturning circulation: A review. Rev. Geophys., 54, 5-63, https://doi.org/ 10.1002/2015RG000493.

Cheng, W., J. C. H. Chiang, and D. X. Zhang, 2013: Atlantic meridional overturning circulation (AMOC) in CMIP5 models: RCP and historical simulations. J. Climate, 26, 7187-7197, https://doi.org/10.1175/JCLI-D-12-00496.1.

Clement, A., K. Bellomo, L. N. Murphy, M. A. Cane, T. Mauritsen, G. Rädel, and B. Stevens, 2015: The Atlantic multidecadal oscillation without a role for ocean circulation. Science, $\mathbf{3 5 0}$, 320-324, https://doi.org/10.1126/science.aab3980.

Colman, R., and B. McAvaney, 2009: Climate feedbacks under a very broad range of forcing. Geophys. Res. Lett., 36, L01702, https://doi.org/10.1029/2008GL036268.

Cunningham, S. A., and Coauthors, 2007: Temporal variability of the Atlantic meridional overturning circulation at $26.5^{\circ} \mathrm{N}$. Science, 317, 935-938, https://doi.org/10.1126/science.1141304.

Danabasoglu, G., S. G. Yeager, Y. O. Kwon, J. J. Tribbia, A. S. Phillips, and J. W. Hurrell, 2012: Variability of the Atlantic meridional overturning circulation in CCSM4. J. Climate, 25, 5153-5172, https://doi.org/10.1175/JCLI-D-11-00463.1.

Day, J. J., J. C. Hargreaves, J. D. Annan, and A. Abe-Ouchi, 2012: Sources of multi-decadal variability in Arctic sea ice extent. Environ. Res. Lett., 7, 034011, https://doi.org/10.1088/ 1748-9326/7/3/034011.

Delworth, T. L., and M. E. Mann, 2000: Observed and simulated multidecadal variability in the Northern Hemisphere. Climate Dyn., 16, 661-676, https://doi.org/10.1007/s003820000075.

, and F. R. Zeng, 2016: The impact of the North Atlantic Oscillation on climate through its influence on the Atlantic meridional overturning circulation. J. Climate, 29, 941-962, https://doi.org/10.1175/JCLI-D-15-0396.1.

_ S. Manabe, and R. J. Stouffer, 1993: Interdecadal variations of the thermohaline circulation in a coupled oceanatmosphere model. J. Climate, 6, 1993-2011, https://oi.org/ 10.1175/1520-0442(1993)006<1993:IVOTTC $>2.0 . C O ; 2$.

, F. R. Zeng, G. A. Vecchi, X. S. Yang, L. P. Zhang, and R. Zhang, 2016: The North Atlantic Oscillation as a driver of rapid climate change in the Northern Hemisphere. Nat. Geosci., 9, 509-512, https://doi.org/10.1038/ngeo2738.

L. P. Zhang, R. Zhang, G. A. Vecchi, and X. S. Yang, 2017: The central role of ocean dynamics in connecting the North Atlantic Oscillation to the extratropical component of the Atlantic multidecadal oscillation. J. Climate, 30, 37893805, https://doi.org/10.1175/JCLI-D-16-0358.1.

Deser, C., R. Knutti, S. Solomon, and A. S. Phillips, 2012: Communication of the role of natural variability in future North American climate. Nat. Climate Change, 2, 775-779, https:// doi.org/10.1038/nclimate1562.

Ding, Y. N., J. A. Carton, G. A. Chepurin, G. Stenchikov, A. Robock, L. T. Sentman, and J. P. Krasting, 2014: Ocean response to volcanic eruptions in Coupled Model Intercomparison Project 5 simulations. J. Geophys. Res. Oceans, 119, 5622-5637, https://doi.org/10.1002/2013JC009780.

Drijfhout, S. S., 2015: Global radiative adjustment after a collapse of the Atlantic meridional overturning circulation. Climate Dyn., 45, 1789-1799, https://doi.org/10.1007/s00382-014-2433-9.

- E. Gleeson, H. A. Dijkstra, and V. Livina, 2013: Spontaneous abrupt climate change due to an atmospheric 
blocking-sea-ice-ocean feedback in an unforced climate model simulation. Proc. Natl. Acad. Sci. USA, 110, 1971319718, https://doi.org/10.1073/pnas.1304912110.

Farneti, R., 2017: Modelling interdecadal climate variability and the role of the ocean. Wiley Interdiscip. Rev.: Climate Change, 8, e441, https://doi.org/10.1002/wcc.441.

Fischer, E. M., U. Beyerle, and R. Knutti, 2013: Robust spatially aggregated projections of climate extremes. Nat. Climate Change, 3, 1033-1038, https://doi.org/10.1038/nclimate2051.

Forster, P. M. D., and K. E. Taylor, 2006: Climate forcings and climate sensitivities diagnosed from coupled climate model integrations. J. Climate, 19, 6181-6194, https://doi.org/10.1175/ JCLI3974.1.

—, T. Andrews, P. Good, J. M. Gregory, L. S. Jackson, and M. Zelinka, 2013: Evaluating adjusted forcing and model spread for historical and future scenarios in the CMIP5 generation of climate models. J. Geophys. Res. Atmos., 118, 11391150, https://doi.org/10.1002/jgrd.50174.

Frölicher, T. L., J. L. Sarmiento, D. J. Paynter, J. P. Dunne, J. P. Krasting, and M. Winton, 2015: Dominance of the Southern Ocean in anthropogenic carbon and heat uptake in CMIP5 models. J. Climate, 28, 862-886, https://doi.org/ 10.1175/JCLI-D-14-00117.1.

Frost, C., and S. G. Thompson, 2000: Correcting for regression dilution bias: Comparison of methods for a single predictor variable. J. Roy. Stat. Soc., 163A, 173-189, https://doi.org/ 10.1111/1467-985X.00164.

Garuba, O. A., and B. A. Klinger, 2016: Ocean heat uptake and interbasin transport of the passive and redistributive components of surface heating. J. Climate, 29, 7507-7527, https:// doi.org/10.1175/JCLI-D-16-0138.1.

_ J. Lu, F. Liu, and H. A. Singh, 2018: The active role of the ocean in the temporal evolution of climate sensitivity. Geophys. Res. Lett., 45, 306-315, https://doi.org/10.1002/2017GL075633.

Gregory, J. M., 2000: Vertical heat transports in the ocean and their effect on time-dependent climate change. Climate Dyn., 16, 501-515, https://doi.org/10.1007/s003820000059.

, and J. F. B. Mitchell, 1997: The climate response to $\mathrm{CO}_{2}$ of the Hadley Centre coupled AOGCM with and without flux adjustment. Geophys. Res. Lett., 24, 1943-1946, https://doi.org/ 10.1029/97GL01930.

_- and Coauthors, 2004: A new method for diagnosing radiative forcing and climate sensitivity. Geophys. Res. Lett., 31, L03205, https://doi.org/10.1029/2003GL018747.

Grise, K. M., and B. Medeiros, 2016: Understanding the varied influence of midlatitude jet position on clouds and cloud radiative effects in observations and global climate models. J. Climate, 29, 9005-9025, https://doi.org/10.1175/JCLI-D-16-0295.1.

Haugstad, A. D., K. C. Armour, D. S. Battisti, and B. E. J. Rose, 2017: Relative roles of surface temperature and climate forcing patterns in the inconstancy of radiative feedbacks. Geophys. Res. Lett., 44, 7455-7463, https://doi.org/10.1002/ 2017GL074372.

Hawkins, E., R. S. Smith, J. M. Gregory, and D. A. Stainforth, 2016: Irreducible uncertainty in near-term climate projections. Climate Dyn., 46, 3807-3819, https://doi.org/10.1007/s00382-015-2806-8.

He, J., M. Winton, G. Vecchi, L. Jia, and M. Rugenstein, 2017: Transient climate sensitivity depends on base climate ocean circulation. J. Climate, 30, 1493-1504, https://doi.org/10.1175/ JCLI-D-16-0581.1.

Heuzé, C., 2017: North Atlantic deep water formation and AMOC in CMIP5 models. Ocean Sci., 13, 609-622, https://doi.org/ 10.5194/os-13-609-2017.
Hobbs, W., M. D. Palmer, and D. Monselesan, 2016: An energy conservation analysis of ocean drift in the CMIP5 global coupled models. J. Climate, 29, 1639-1653, https://doi.org/ 10.1175/JCLI-D-15-0477.1.

Hurrell, J. W., and Coauthors, 2013: The Community Earth System Model: A framework for collaborative research. Bull. Amer. Meteor. Soc., 94, 1339-1360, https://doi.org/10.1175/ BAMS-D-12-00121.1.

Johns, W. E., and Coauthors, 2011: Continuous, array-based estimates of Atlantic Ocean heat transport at $26.5^{\circ}$ N. J. Climate, 24, 2429-2449, https://doi.org/10.1175/2010JCLI3997.1.

Kang, S. M., and S. P. Xie, 2014: Dependence of climate response on meridional structure of external thermal forcing. J. Climate, 27, 5593-5600, https://doi.org/10.1175/JCLI-D-13-00622.1.

Kim, W. M., S. Yeager, P. Chang, and G. Danabasoglu, 2018: Lowfrequency North Atlantic climate variability in the Community Earth System Model Large Ensemble. J. Climate, 31, 787-813, https://doi.org/10.1175/JCLI-D-17-0193.1.

Klein, S. A., and D. L. Hartmann, 1993: The seasonal cycle of low stratiform clouds. J. Climate, 6, 1587-1606, https://doi.org/ 10.1175/1520-0442(1993)006<1587:TSCOLS $>2.0$. CO;2.

Kleppin, H., M. Jochum, B. Otto-Bliesner, C. A. Shields, and S. Yeager, 2015: Stochastic atmospheric forcing as a cause of Greenland climate transitions. J. Climate, 28, 7741-7763, https://doi.org/10.1175/JCLI-D-14-00728.1.

Knight, J. R., R. J. Allan, C. K. Folland, M. Vellinga, and M. E. Mann, 2005: A signature of persistent natural thermohaline circulation cycles in observed climate. Geophys. Res. Lett., 32, L20708, https://doi.org/10.1029/2005GL024233.

Knutson, T. R., R. Zhang, and L. W. Horowitz, 2016: Prospects for a prolonged slowdown in global warming in the early $21 \mathrm{st}$ century. Nat. Commun., 7, 13676, https://doi.org/10.1038/ ncomms13676.

Knutti, R., and T. F. Stocker, 2000: Influence of the thermohaline circulation on projected sea level rise. J. Climate, 13, 1997-2001, https://doi.org/10.1175/1520-0442(2000)013<1997: IOTTCO $>2.0 . \mathrm{CO} ; 2$.

Kostov, Y., K. C. Armour, and J. Marshall, 2014: Impact of the Atlantic meridional overturning circulation on ocean heat storage and transient climate change. Geophys. Res. Lett., 41, 2108-2116, https://doi.org/10.1002/2013GL058998.

Laurian, A., S. S. Drijfhout, W. Hazeleger, and R. van Dorland, 2009: Global surface cooling: The atmospheric fast feedback response to a collapse of the thermohaline circulation. Geophys. Res. Lett., 36, L20708, https://doi.org/10.1029/2009GL040938.

Livezey, R. E., and W. Y. Chen, 1983: Statistical field significance and its determination by Monte Carlo techniques. Mon. Wea. Rev., 111, 46-59, https://doi.org/10.1175/1520-0493(1983)111<0046: SFSAID $>2.0 . \mathrm{CO} ; 2$.

Mahajan, S., R. Zhang, and T. L. Delworth, 2011: Impact of the Atlantic meridional overturning circulation (AMOC) on Arctic surface air temperature and sea ice variability. J. Climate, 24, 6573-6581, https://doi.org/10.1175/2011JCLI4002.1.

Marini, C., and C. Frankignoul, 2014: An attempt to deconstruct the Atlantic multidecadal oscillation. Climate Dyn., 43, 607625, https://doi.org/10.1007/s00382-013-1852-3.

Marshall, D. P., and L. Zanna, 2014: A conceptual model of ocean heat uptake under climate change. J. Climate, 27, 8444-8465, https://doi.org/10.1175/JCLI-D-13-00344.1.

Marshall, J., J. R. Scott, K. C. Armour, J. M. Campin, M. Kelley, and A. Romanou, 2015: The ocean's role in the transient response of climate to abrupt greenhouse gas forcing. Climate Dyn., $\mathbf{4 4}$, 2287-2299, https://doi.org/10.1007/s00382-014-2308-0. 
Medhaug, I., M. B. Stolpe, E. M. Fischer, and R. Knutti, 2017: Reconciling controversies about the 'global warming hiatus.' Nature, 545, 41-47, https://doi.org/10.1038/nature22315.

Msadek, R., W. E. Johns, S. G. Yeager, G. Danabasoglu, T. L. Delworth, and A. Rosati, 2013: The Atlantic meridional heat transport at $26.5^{\circ} \mathrm{N}$ and its relationship with the MOC in the RAPID array and the GFDL and NCAR coupled models. J. Climate, 26, 4335-4356, https://doi.org/10.1175/ JCLI-D-12-00081.1.

Muir, L. C., and A. V. Fedorov, 2017: Evidence of the AMOC interdecadal mode related to westward propagation of temperature anomalies in CMIP5 models. Climate Dyn., 48, 15171535, https://doi.org/10.1007/s00382-016-3157-9.

Neale, R. B., and Coauthors, 2010: Description of the NCAR Community Atmosphere Model (CAM 4.0). NCAR Tech. Note NCAR/TN-485+STR, 224 pp., http://www.cesm.ucar.edu/ models/ccsm4.0/cam/docs/description/cam4_desc.pdf.

O'Reilly, C. H., M. Huber, T. Woollings, and L. Zanna, 2016: The signature of low-frequency oceanic forcing in the Atlantic multidecadal oscillation. Geophys. Res. Lett., 43, 2810-2818, https://doi.org/10.1002/2016GL067925.

Paynter, D., and T. L. Frölicher, 2015: Sensitivity of radiative forcing, ocean heat uptake, and climate feedback to changes in anthropogenic greenhouse gases and aerosols. J. Geophys. Res. Atmos., 120, 9837-9854, https://doi.org/10.1002/ 2015JD023364.

Rahmstorf, S., J. E. Box, G. Feulner, M. E. Mann, A. Robinson, S. Rutherford, and E. J. Schaffernicht, 2015: Exceptional twentieth-century slowdown in Atlantic Ocean overturning circulation. Nat. Climate Change, 5, 475-480, https://doi.org/ 10.1038/nclimate2554.

Raper, S. C. B., J. M. Gregory, and R. J. Stouffer, 2002: The role of climate sensitivity and ocean heat uptake on AOGCM transient temperature response. J. Climate, 15, 124-130, https://doi.org/ 10.1175/1520-0442(2002)015<0124:TROCSA > 2.0.CO;2.

Roberts, M. J., H. T. Hewitt, P. Hyder, D. Ferreira, S. A. Josey, M. Mizielinski, and A. Shelly, 2016: Impact of ocean resolution on coupled air-sea fluxes and large-scale climate. Geophys. Res. Lett., 43, $10430-10438$, https://doi.org/10.1002/ 2016GL070559.

Rose, B. E. J., and L. Rayborn, 2016: The effects of ocean heat uptake on transient climate sensitivity. Curr. Climate Change Rep., 2, 190-201, https://doi.org/10.1007/s40641-016-0048-4.

—, K. C. Armour, D. S. Battisti, N. Feldl, and D. D. B. Koll, 2014: The dependence of transient climate sensitivity and radiative feedbacks on the spatial pattern of ocean heat uptake. Geophys. Res. Lett., 41, 1071-1078, https://doi.org/10.1002/ 2013 GL058955.

Rugenstein, M. A. A., M. Winton, R. J. Stouffer, S. M. Griffies, and R. Hallberg, 2013: Northern high-latitude heat budget decomposition and transient warming. J. Climate, 26, 609-621, https://doi.org/10.1175/JCLI-D-11-00695.1.

_ - K. Caldeira, and R. Knutti, 2016: Dependence of global radiative feedbacks on evolving patterns of surface heat fluxes. Geophys. Res. Lett., 43, 9877-9885, https://doi.org/10.1002/ 2016 GL070907.

Schmith, T., S. T. Yang, E. Gleeson, and T. Semmler, 2014: How much have variations in the meridional overturning circulation contributed to sea surface temperature trends since 1850 ? A study with the EC-Earth global climate model. J. Climate, 27, 6343-6357, https://doi.org/10.1175/JCLI-D-13-00651.1.

Soden, B. J., A. J. Broccoli, and R. S. Hemler, 2004: On the use of cloud forcing to estimate cloud feedback. J. Climate, 17,
3661-3665, https://doi.org/10.1175/1520-0442(2004)017<3661: OTUOCF $>2.0 . \mathrm{CO} ; 2$.

Stainforth, D. A., M. R. Allen, E. R. Tredger, and L. A. Smith, 2007: Confidence, uncertainty and decision-support relevance in climate predictions. Philos. Trans. Roy. Soc. London, $\mathbf{3 6 5 A}$, 2145-2161, https://doi.org/10.1098/rsta.2007.2074.

Stolpe, M. B., I. Medhaug, and R. Knutti, 2017: Contribution of Atlantic and Pacific multidecadal variability to twentiethcentury temperature changes. J. Climate, 30, 6279-6295, https://doi.org/10.1175/JCLI-D-16-0803.1.

Stouffer, R. J., and Coauthors, 2006: Investigating the causes of the response of the thermohaline circulation to past and future climate changes. J. Climate, 19, 1365-1387, https://doi.org/ 10.1175/JCLI3689.1.

Tandon, N. F., and P. J. Kushner, 2015: Does external forcing interfere with the AMOC's influence on North Atlantic sea surface temperature? J. Climate, 28, 6309-6323, https://doi.org/ 10.1175/JCLI-D-14-00664.1.

Taylor, K. E., R. J. Stouffer, and G. A. Meehl, 2012: An overview of CMIP5 and the experiment design. Bull. Amer. Meteor. Soc., 93, 485-498, https://doi.org/10.1175/BAMS-D-11-00094.1.

Trossman, D. S., J. B. Palter, T. M. Merlis, Y. Huang, and Y. Xia, 2016: Large-scale ocean circulation-cloud interactions reduce the pace of transient climate change. Geophys. Res. Lett., 43, 3935-3943, https://doi.org/10.1002/2016GL067931.

Watanabe, M., Y. Kamae, M. Yoshimori, A. Oka, M. Sato, M. Ishii, T. Mochizuki, and M. Kimoto, 2013: Strengthening of ocean heat uptake efficiency associated with the recent climate hiatus. Geophys. Res. Lett., 40, 3175-3179, https://doi.org/10.1002/ grl.50541.

Wilks, D. S., 2016: "The stippling shows statistically significant grid points": How research results are routinely overstated and overinterpreted, and what to do about it. Bull. Amer. Meteor. Soc., 97, 2263-2273, https://doi.org/10.1175/ BAMS-D-15-00267.1.

Winton, M., 2003: On the climatic impact of ocean circulation. J. Climate, 16, 2875-2889, https://doi.org/10.1175/1520-0442(2003) $016<2875$ :OTCIOO $>2.0$.CO;2.

_ K. Takahashi, and I. M. Held, 2010: Importance of ocean heat uptake efficacy to transient climate change. J. Climate, 23, 2333-2344, https://doi.org/10.1175/2009JCLI3139.1.

, S. M. Griffies, B. L. Samuels, J. L. Sarmiento, and T. L. Frölicher, 2013: Connecting changing ocean circulation with changing climate. J. Climate, 26, 2268-2278, https://doi.org/10.1175/ JCLI-D-12-00296.1.

— , W. G. Anderson, T. L. Delworth, S. M. Griffies, W. J. Hurlin, and A. Rosati, 2014: Has coarse ocean resolution biased simulations of transient climate sensitivity? Geophys. Res. Lett., 41, 8522-8529, https://doi.org/10.1002/2014GL061523.

Wood, R., and C. S. Bretherton, 2006: On the relationship between stratiform low cloud cover and lower-tropospheric stability. J. Climate, 19, 6425-6432, https://doi.org/10.1175/ JCLI3988.1.

Woollings, T., J. M. Gregory, J. G. Pinto, M. Reyers, and D. J. Brayshaw, 2012: Response of the North Atlantic storm track to climate change shaped by ocean-atmosphere coupling. Nat. Geosci., 5, 313-317, https://doi.org/10.1038/ngeo1438.

Xie, P., and G. K. Vallis, 2012: The passive and active nature of ocean heat uptake in idealized climate change experiments. Climate Dyn., 38, 667-684, https://doi.org/10.1007/ s00382-011-1063-8.

Yeager, S. G., A. R. Karspeck, and G. Danabasoglu, 2015: Predicted slowdown in the rate of Atlantic sea ice loss. 
Geophys. Res. Lett., 42, 10 704-10 713, https://doi.org/ 10.1002/2015GL065364.

Zhang, R., 2010: Latitudinal dependence of Atlantic meridional overturning circulation (AMOC) variations. Geophys. Res. Lett., 37, L16703, https://doi.org/10.1029/2010GL044474.

,2015: Mechanisms for low-frequency variability of summer Arctic sea ice extent. Proc. Natl. Acad. Sci. USA, 112, 45704575, https://doi.org/10.1073/pnas.1422296112.

, T. L. Delworth, and I. M. Held, 2007: Can the Atlantic Ocean drive the observed multidecadal variability in Northern
Hemisphere mean temperature? Geophys. Res. Lett., 34, L02709, https://doi.org/10.1029/2006GL028683.

, S. M. Kang, and I. M. Held, 2010: Sensitivity of climate change induced by the weakening of the Atlantic meridional overturning circulation to cloud feedback. J. Climate, 23, 378389, https://doi.org/10.1175/2009JCLI3118.1.

, R. Sutton, G. Danabasoglu, T. L. Delworth, W. M. Kim, J. Robson, and S. G. Yeager, 2016: Comment on "The Atlantic multidecadal oscillation without a role for ocean circulation." Science, 352, 1527, https://doi.org/10.1126/science.aaf1660. 